\title{
$\infty \sqrt{1}$ Stroke and \\ Intravenous tirofiban therapy for patients with capsular warning syndrome
}

Wei Li, Ya Wu, Xiao-Shu Li, Cheng-Chun Liu, Shu-Han Huang, Chun-Rong Liang, Huan Wang, Li-Li Zhang, Zhi-Qiang Xu, Yan-Jiang Wang, Meng Zhang

To cite: Li W, Wu Y, Li X-S, et al. Intravenous tirofiban therapy for patients with capsular warning syndrome. Stroke and Vascular Neurology 2019;4: e000163. doi:10.1136/svn-2018-000163

- Additional material is published online only. To view please visit the journal online (http://dx.doi.org/10.1136/svn2018-000163).

WL and YW contributed equally.

Received 17 April 2018

Revised 23 October 2018 Accepted 5 November 2018 Published Online First 9 January 2019

\section{ABSTRACT}

Background Capsular warning syndrome (CWS) is defined as recurrent episodes of transient ischaemic attacks $\geq 3$ times during a short time frame. There is no effective therapy to stop these attacks. We, herein, report our experience of using intravenous tirofiban to treat CWS. Methods All patients with CWS in our hospital from January 2013 to September 2017 were reviewed. Patients in tirofiban group (T-group) were treated by intravenous tirofiban at $0.4 \mu \mathrm{g} / \mathrm{kg} / \mathrm{min}$ for $30 \mathrm{~min}$ followed by $0.1-0.15 \mu \mathrm{g} / \mathrm{kg} / \mathrm{min}$ infusion. Other treatments (non-Tgroup) included thrombolytic, oral antiplatelet agents and anticoagulant. Intracerebral haemorrhage (ICH), systematic bleeding, new attacks after treatment, National Institutes of Health Stroke Scale (NIHSS) scores at 24 hours and modified Rankin Scales (mRSs) at 3 months were recorded. Descriptive statistics were used for analysis.

Results of 23 patients qualified ( 15 in T-group, 8 in non-T-group), the duration of symptoms ranged from 2 to 100 min before treatments. After treatment, in T-group, four patients (26.7\%) had recurrent attacks, and NIHSS scores were 0 in 11 patients (73.3\%) at 24 hours. All patients reached a favourable outcome (mRS $\leq 2$ at 3 months. In non-T-group, five patients (62.5\%) had new attacks. NIHSS scores were 0 in two patients $(25 \%)$ at 24 hours. At 3 months, seven patients (87.5\%) reached a favourable outcome. Neither ICH nor systematic bleeding or thrombocytopaenia occurred in both groups of patients. Conclusions Intravenous tirofiban can be a potentially effective and safe therapy to stop early symptomatic fluctuations and shorten the duration of functional deficits in patients with CWS

\section{INTRODUCTION}

Capsular warning syndrome (CWS) is defined as recurrent stereotyped episodes of at least three transient ischaemic attacks (TIAs) during a short time frame, affecting two or more anatomical regions such as patient's face, arm and leg, but without any cortical symptoms. ${ }^{1}$ With the widespread use of magnetic rensonance imaging (MRI), anatomical areas that often related to the CWS have been identified to include internal capsule, pons or anywhere in the corticospinal tract. ${ }^{2}$ Actually, the current definition of CWS should include patients with TIA and those with transient symptoms of infarction because most of them were diagnosed clinically without the benefit of obtaining an MRI before treatments. ${ }^{3}$
Although CWS occurs in only about $1.5 \%$ of patients with transient symptoms, the risk of developing into a permanent deficit is high and often with poor prognosis. ${ }^{4}$ Moreover, the frequently recurrent attacks cause significant disability and great anxiety to patients who experience these episodes. Different therapies have been proposed, including anticoagulation, antiplatelet therapies and even recombinant tissue plasminogen activator (rt-PA), in order to stop the process of CWS. Unfortunately, there is no confirmed effective therapy so far. ${ }^{5-11}$ One retrospective study enrolled 51 patients with fluctuating lacunar syndromes (similar to CWS), and who were treated with intravenous abciximab (an antibody fragment binds to the glycoprotein (GP) IIb/IIIa receptor) suggested that abciximab might be beneficial and safe. ${ }^{12}$ Tirofiban is a fast-acting highly selective non-peptide GP IIb/IIIa receptor antagonist that is presumably safer than abciximab because its effect on platelet aggregation was reversible. ${ }^{13} 14$ Intravenous tirofiban was safe, and potentially effective when used alone or combined with other agents in several studies for treating patients with acute ischaemic stroke. ${ }^{15-17}$ We, herein, report our preliminary experience of using intravenous tirofiban to treat patients with CWS, and compared with the outcomes of eight patients treated with other methods at our stroke centre. A brief review of the literatures on this topic was also completed (online supplementary table 1).

\section{PATIENTS AND METHODS}

This is a retrospective study. Data of all patients presenting with a diagnosis of CWS from January 2013 to September 2017 were reviewed (Table 1). CWS was defined as having at least three stereotyped episodes in 24hours with either motor hemiparesis, sensory hemiparesis, sensory-motor hemiparesis or ataxic hemiparesis affecting two or more parts of a patient, including the face, arm or leg, but without cortical symptoms. Hemiplegic migraines and focal seizures were 
excluded. Head computed tomography (CT) scan and CT angiography (CTA) were performed to exclude any intracerebral haemorrhage (ICH) and detect the stenosis or occlusion of a large vessel before treatment. Most patients had head MRI within 48 hours of admission.

The patients who received intravenous tirofiban were divided into two groups (Table 2). In tirofiban group (T-group) I, patients received intravenous tirofiban bolus $(0.4 \mu \mathrm{g} / \mathrm{kg}$ body weight per minute) over $30 \mathrm{~min}$ followed by a continuous intravenous infusion $(0.1 \mu \mathrm{g} /$ $\mathrm{kg}$ body weight per minute) for 24 hours. Overlapped with tirofiban infusion for 4 hours, these patients also received oral aspirin $(100 \mathrm{mg})$ and clopidogrel $(300 \mathrm{mg})$ as the loading dose, followed by aspirin $100 \mathrm{mg}$ plus clopidogrel $75 \mathrm{mg}$ per day for 21 days and only aspirin $100 \mathrm{mg}$ (or clopidogrel $75 \mathrm{mg}$ ) per day for the next 69 days. In T-group II, patients initially had intravenous rt-PA but developed worsening of their neurological deficits or fluctuating symptoms. Tirofiban was initiated and followed with the same oral antiplatelet strategy. They all had additional CT or MRI to rule out any ICH before tirofiban was started. For those patients who refused tirofiban, they were treated with intravenous rt-PA alone, oral antiplatelet agents, anticoagulation and intravenous hydration (table 3). Same oral antiplatelet therapy was continued for 3 months in non-T-group as well.

Besides the antithrombotic therapy, all patients received statin (atorvastatin $40 \mathrm{mg}$ or rosuvastatin $20 \mathrm{mg}$ ) on admission and followed with daily oral atorvastatin $20 \mathrm{mg}$ or rosuvastatin $10 \mathrm{mg}$. All patients had National Institutes of Health Stroke Scale (NIHSS) every 2 hours in the first 24 hours after admission and every day before discharge or when there was a recurrent episode. At 3-month follow-up, a modified Rankin Scale (mRS) was performed. Any type of ICH, system bleeding and thrombocytopaenia were monitored during hospitalisation.

The AHA Guidelines for the Early Management of Patients with Acute Ischemic Stroke gave a weak recommendation of intravenous alteplase treatment for patients with rapidly improving stroke symptoms. ${ }^{18}$ Only six patients accepted intravenous alteplase treatment in our study. All patients in T-group were consented before tirofiban administration.

Descriptive statistics were used for analysis.

\section{RESULTS}

Of 23 patients included, 17 (73.9\%) were male and their mean age was 58.1 (range 28-82). Their stroke risk factors were listed in tables 1 and 2. No patients had history of cardiac arrhythmia or evidence of atrial fibrillation on the continuous ECG monitoring after admission. The number of CWS episodes ranged from 3 to more than 9 times within 24 hours before the treatments. The duration of each episode ranged from 2 to $100 \mathrm{~min}$.

Cerebral atherosclerosis was identified by CTA in $82.6 \%$ of all patients (14/15 in T-group, 5/8 in no-T-group). Follow-up MRI of head was done in 14/15 patients in the
Table 1 Clinical characteristics of patients with capsular warning syndrome

\begin{tabular}{lll}
\hline & $\begin{array}{l}\text { Tirofiban } \\
\text { group } \\
\text { N (\%) }\end{array}$ & $\begin{array}{l}\text { Non- } \\
\text { tirofiban } \\
\text { group } \\
\text { N (\%) }\end{array}$ \\
\hline Male sex & $11(73.3)$ & $6(75.0)$ \\
\hline Hypertension & $9(60)$ & $5(62.5)$ \\
\hline Diabetes mellitus & 0 & $2(25.0)$ \\
\hline Hypercholesterolaemia & $11(73.3)$ & $6(75.0)$ \\
\hline Previous ischaemic stroke & 0 & 0 \\
\hline Ischaemic heart disease & 0 & 0 \\
\hline Atrial fibrillation & 0 & 0 \\
\hline Peripheral vascular disease & 0 & 0 \\
\hline Current alcohol use & $10(67.7)$ & $3(37.5)$ \\
\hline Smoking & $7(46.7)$ & $3(37.5)$ \\
\hline Previous antiplatelet therapy & $2(13.3)$ & 0 \\
\hline Previous anticoagulant therapy & 0 & 0 \\
\hline Previous antihypertensive & $4(26.7)$ & 0 \\
therapy & & \\
\hline Previous treatment with statins & $2(13.3)$ & 0 \\
\hline Previous antiplatelet and statins & $2(13.3)$ & 0 \\
therapy & & \\
\hline & & \\
\hline
\end{tabular}

T-group, 7/8 in non-T-group, 3 patients $(14.3 \%)$ were negative; 3 patients (14.3\%) had high signal on diffusion-weighted imaging in paramedian pons; $1(4.8 \%)$ in the territory of lenticulostriate arteries and $14(66.7$ $\%)$ in the territory of anterior choroidal artery (AChA) (table 2). Two patients refused MRI but had a follow-up head CT scan, which showed no ICH after therapy. For the safety outcomes, no ICH and systemic bleeding took place during their hospitalisation. No one had thrombocytopaenia (ie, platelet count dropped below $<100 \times 10^{\wedge} 9 / \mathrm{L}$ ) before discharge.

In T-group I, 11 patients received tirofiban directly post-CT scan. Among them, six patients started treatment while having symptoms. After infusion of tirofiban, four of them recovered completely with no new fluctuating symptoms. Two patients (\#2 and \#4) had partial recovery (NIHSS=2 and 1, respectively) at 24 hours. Five patients received tirofiban treatment between the attacks. Among them, one (\#3) developed new episodes during maintenance infusion period $(0.1 \mu \mathrm{g} / \mathrm{kg} / \mathrm{min})$ and the other one (\#11) had an attack at 3 hours after completing a 24-hour infusion. Both patients (\#3 and \#11) recovered quickly after an additional intravenous loading dose of tirofiban. Considering the possibility that recurrent episodes might be related to a much higher activity of platelets, after the second loading dose, maintenance dose was adjusted to $0.15 \mu \mathrm{g} / \mathrm{kg} / \mathrm{min}$ in patient \#3, and their total infusion time was also prolonged to 36 hours. For patients \#11, the maintenance infusion was continued for another 


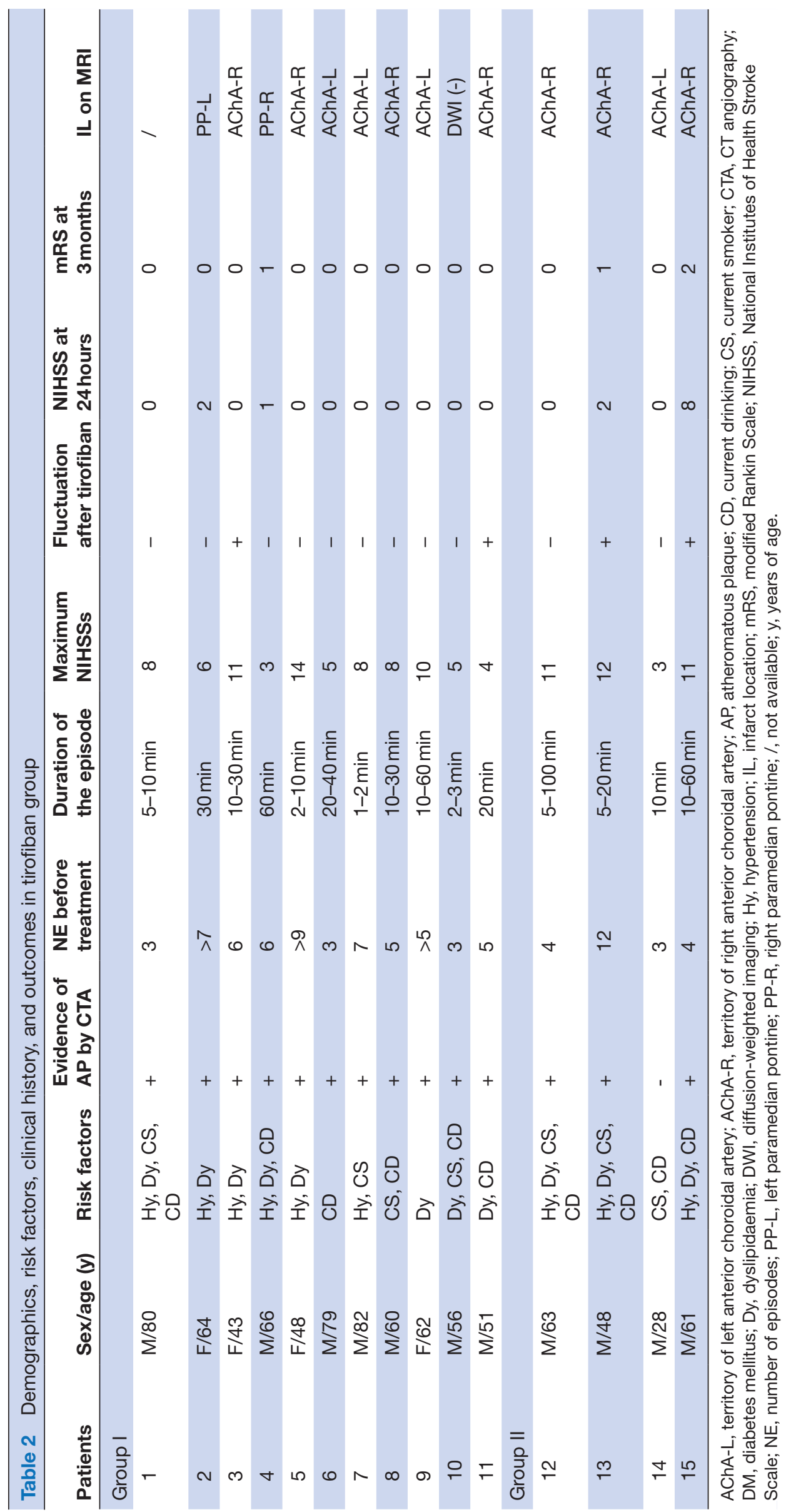


24 hours after the second loading dose. Fluctuating symptoms then stopped.

In T-group II $(\mathrm{n}=4)$, patients received intravenous rt-PA first, but their neurological symptoms worsened. NIHSS scores changed from 5 to 11 after intravenous rt-PA in one (\#15) patient. One patient (\#13) had intravenous rt-PA followed with dual antiplatelet agents immediately (aspirin $100 \mathrm{mg}$ plus clopidogrel $300 \mathrm{mg}$ ). However, his symptoms were still fluctuating during the next 24 hours. The other two patients (\#12 and \#14) also had repeated recurrent symptoms after intravenous rt-PA. After starting intravenous tirofiban, fluctuating symptoms in two patients (\#12 and \#14) were well controlled. During the maintenance infusion stage, two patients (\#13 and \#15) had fluctuations of symptoms again. They were given another loading dose of tirofiban, followed by a higher dose of maintenance infusion $(0.15 \mu \mathrm{g} / \mathrm{kg} / \mathrm{min})$ and prolonged infusion time (up to 36 hours).

A day after the initiation of tirofiban, NIHSS scores was 0 in $11(73.3 \%)$ patients in the T-group (including T-group I and T-group II). At 3 months, a favourable outcome $(\mathrm{mRS} \leq 2)$ was observed in all of them $(\mathrm{mRS}=0$ in 12 patients and $m R S=1$ in 2 patients) (table 2 ).

In the non-T-group, including those received intravenous rt-PA only, five patients $(62.5 \%)$ had symptom fluctuation with fixed neurological deficits. At 24 hours, only 2/8 $(25 \%)$ patients completely recovered (NIHSS $=0$ ). At 3 months, $7 / 8(87.5 \%) \quad(\mathrm{mRS}=0$ in four patients and $m R S=1$ in three patients) patients had favourable outcome ( $\mathrm{mRS} \leq 2)($ table 3$)$.

Besides the data from our own centre, the outcomes of the patients with CWS by different treatments reported in the PubMed database (only in English) were summarised in online supplementary table 1.

\section{DISCUSSION}

Although CWS is a relatively rare clinical syndrome and the symptoms might resolve spontaneously, the repeated attacks could result in permanent neurological deficits. The prognosis is poor and with a 7-day risk of stroke up to $60 \%{ }^{4}$ There are different hypotheses of the underlying pathophysiology of CWS. Therefore, different strategies have been considered, including thrombolysis, anticoagulation, dual oral antiplatelet agents, raising blood pressure or aggressive intravenous hydration (online supplementary table 1). However, to the best of our knowledge, currently, there is no effective strategy.

In our study, six patients (four in T-group II, two in non-T-group) had intravenous rt-PA at first but still had repeated attacks. One patient (\#15) even had neurological deterioration (NIHSS increased from 5 to 11). The other five patients continue to have fluctuating symptoms during and after intravenous rt-PA. Our findings were consistent with a previous report in which nine patients treated by intravenous rt-PA but continue to have worsening of neurological function. ${ }^{11}$ Thrombolytic agents could activate platelet aggregation that in turn would

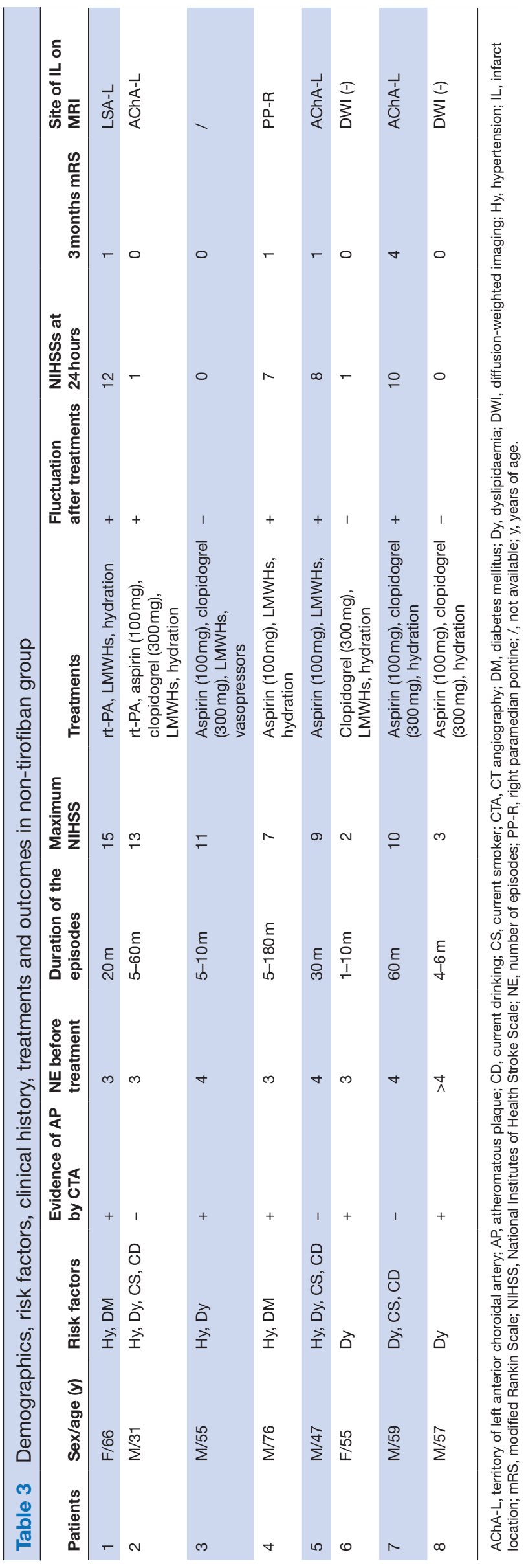


cause the reocclusion of the recanalised artery by intravenous rt-PA. ${ }^{19}$ One multicentre study showed $75 \%$ of the 12 patients treated by intravenous rt-PA had a favourable outcome. ${ }^{10}$ However, in this study, the inclusion criterion was defined as the succession of at least three recurrent episodes within a 72-hour period, which was different from those used a 24-hour time frame. The relative longer time frame might contribute to a higher rate of the good outcome.

Recent studies using high-resolution MRI in patients with CWS suggested that even when traditional cerebral vascular angiography (including CTA, magnetic resonance angiography or digital subtraction angiography) did not show any significant abnormality of large intracranial arteries, atherosclerotic plaques were discovered at branching point of the penetrating arteries, which could partially explain the underlying pathophysiology of CWS. ${ }^{20}{ }^{21}$ These stereotypical attacks might be caused by the 'thrombotic' process and overactivation of platelets. In fact, in our case series, significant atherosclerotic changes (detected by CTA) were more common compared with those reported in the literatures $(78.3 \%$ vs $14 \%) .{ }^{10}$ Although several reports showed the effectiveness of a combination of aspirin and loading dose of clopidogrel in some patients with CWS, ${ }^{22}{ }^{23}$ the results were inconsistent. Such combination therapy was not consistently effective in our study either. We speculated that such inconsistency might be related to the limited efficacy of oral antiplatelet agents. Therefore, tirofiban, a more fast-acting and powerful platelet GP IIb/ IIIa receptor inhibitor, might be a better agent to treat patients with CWS.

In our study, patients in T-group I received intravenous tirofiban right after their admission. The clinical fluctuation was successfully stopped in $81.8 \%(9 / 11)$ of patients during the tirofiban infusion. In T-group II, intravenous tirofiban was administrated to remedy the failed therapy by intravenous rt-PA. Patients in this group had either partial or complete recovery after the additional tirofiban treatment. Notably, new episodes occurred during the maintenance phase of intravenous tirofiban or several hours after tirofiban stopped in 26.7\% (4/15) of patients but quickly resolved after another loading dose of tirofiban. This phenomenon indirectly confirmed the likelihood of platelet hyperactivity and provided further evidence for the need of aggressive antiplatelet therapy in patients with CWS. Besides, continuous infusion (24-48 hours) with the repeated loading dose of tirofiban in this cohort of patients with CWS was safe. Neither any type of haemorrhage transformation nor thrombocytopaenia occurred before discharge.

From our study, oral antiplatelet agents, anticoagulation and even thrombolysis were not effective, as findings reported in the literatures (table 3 and online supplementary table 1). However, at 3 months follow-up, all patients in the T-group and $87.5 \%$ of patients in the non-T-group reached a favourable outcome $(\mathrm{mRS} \leq 2)$. This high rate of a favourable outcome in our study might be related to the use of dual antiplatelet therapy (aspirin $100 \mathrm{mg}$ and clopidogrel $75 \mathrm{mg}$ per day for 21 days), an important strategy to combat hyperactive platelets in patients with CWS.

Lacunar infarct was identified in $90.5 \%(19 / 21)$ of the patients who had a follow-up MRI scan. Interestingly, most of the lesions $(66.7 \%)$ were in the territory of AChA in our study. It has been reported that acute cerebral infarction located in this area had higher risk of clinical progression and poor outcome even intravenous thrombolytic therapy was given. ${ }^{24}$ We speculated that the earlier use of more powerful antiplatelet agents should be considered after traditional thrombolytic therapy in patients with acute infarction in the territory of AChA, regardless if these patients had repeated TIAs prior to their final stroke.

\section{CONCLUSION}

Intravenous tirofiban appeared to be effective and safe in stopping recurrent and fluctuating symptoms in patients with CWS. We speculated that hyperactivity of platelets might play an important role during the process of CWS, especially in patients with evidence of intracranial atherosclerosis and postintravenous rt-PA treatment. Antiplatelet therapy during the acute phase with tirofiban and dual antiplatelet therapy during the subacute phase might be an effective and safe strategy of treating and preventing CWS. However, this positive result could not be confirmed by our series since only a small number of patients was treated without a control group. Another limitation of our study was the lack of direct laboratory evidence of inhibition of platelet activity by intravenous tirofiban. A multicentre registry or prospective trial is needed to confirm the findings from our study.

Correction notice This article has been corrected since it was published. There was an error to data in the Results section of the Abstract.

Contributors MZ and WL conceived the study. WL drafted the manuscript. YW collected the data and carried out data analysis. X-SL, C-CL, S-HH, C-RL, L-LZ, Z-QX and Y-JW collected the data. All authors read and approved the final manuscript.

Funding This project is supported by NSFC81400892 and Chongqing Science and Technology, grant(2017jstg04).

Competing interests None declared.

Patient consent for publication Obtained.

Ethics approval Intravenous tirofiban treatment in patients with CWS was approved by the medical ethics committee of Daping Hospital of the Army Medical University. Provenance and peer review Not commissioned; externally peer reviewed. Data sharing statement № additional data are available.

Open access This is an open access article distributed in accordance with the Creative Commons Attribution Non Commercial (CC BY-NC 4.0) license, which permits others to distribute, remix, adapt, build upon this work non-commercially, and license their derivative works on different terms, provided the original work is properly cited, appropriate credit is given, any changes made indicated, and the use is non-commercial. See: http://creativecommons.org/licenses/by-nc/4.0/.

\section{REFERENCES}

1. Donnan GA, O'Malley HM, Quang L, et al. The capsular warning syndrome: pathogenesis and clinical features. Neurology 1993;43:957-62. 
2. Staaf G, Geijer B, Lindgren A, et al. Diffusion-weighted MRI findings in patients with capsular warning syndrome. Cerebrovasc Dis 2004;17:1-8.

3. Easton JD, Saver JL, Albers GW, et al. Definition and evaluation of transient ischemic attack: a scientific statement for healthcare professionals from the American Heart Association/American Stroke Association Stroke Council; Council on Cardiovascular Surgery and Anesthesia; Council on Cardiovascular Radiology and Intervention; Council on Cardiovascular Nursing; and the Interdisciplinary Council on Peripheral Vascular Disease. The American Academy of Neurology affirms the value of this statement as an educational tool for neurologists. Stroke 2009;40:2276.

4. Paul NL, Simoni M, Chandratheva A, et al. Population-based study of capsular warning syndrome and prognosis after early recurrent TIA. Neurology 2012;79:1356-62.

5. Vivanco-Hidalgo RM, Rodriguez-Campello A, Ois A, et al. Thrombolysis in capsular warning syndrome. Cerebrovasc Dis 2008;25:508-10.

6. Gutiérrez Ruano B, García Pastor A, Villanueva Osorio JA, et al. [Intravenous thrombolysis in capsular warning syndrome: is it beneficial?]. Neurologia 2013;28:444-6.

7. González Hernández A, Fabre Pi O, López Fernández JC, et al. [Thrombolysis in capsular warning syndrome]. Med Clin 2010;134:612-3.

8. González Hernández A, Fabre Pi O, Cabrera Naranjo F, et al. Intravenous thrombolysis with recombinant tissue plasminogen activator in vascular warning syndromes. Neurologia 2014;29:334-8.

9. Enriquez-Marulanda A, Amaya-Gonzalez P, Orozco JL. Pontine warning syndrome: a chameleon of ischemic stroke. Neurologist 2016;21:93-6.

10. Camps-Renom P, Delgado-Mederos R, Martínez-Domeño A, et al. Clinical characteristics and outcome of the capsular warning syndrome: a multicenter study. Int J Stroke 2015;10:571-5.

11. Tassi R, Cerase A, Acampa M, et al. Stroke warning syndrome: 18 new cases. J Neurol Sci 2013;331(1-2):168-71.

12. Parker S, Patidar B, Abou-Hanna J, et al. Abciximab for fluctuating lacunar syndrome (P05.245). Neurology 2013;80:P05.245-P05.45.
13. Ferguson JJ, Waly HM, Wilson JM. Fundamentals of coagulation and glycoprotein Ilb/llla receptor inhibition. Am Heart $J$ 1998; 135:s35-s42.

14. Junghans U, Seitz RJ, Aulich A, et al. Bleeding risk of tirofiban, a nonpeptide GPIlb/llla platelet receptor antagonist in progressive stroke: an open pilot study. Cerebrovasc Dis 2001;12:308-12.

15. Li W, Lin L, Zhang M, et al. Safety and preliminary efficacy of early tirofiban treatment after alteplase in acute ischemic stroke patients. Stroke 2016;47:2649-51.

16. Lin L, Li W, Liu CC, et al. Safety and preliminary efficacy of intravenous tirofiban in acute ischemic stroke patient without arterial occlusion on neurovascular imaging studies. J Neurol Sci 2017:383:175-9.

17. Seitz RJ, Hamzavi M, Junghans $U$, et al. Thrombolysis with recombinant tissue plasminogen activator and tirofiban in stroke: preliminary observations. Stroke 2003;34:1932-5.

18. Jauch EC, Saver JL, Adams HP, et al. Guidelines for the early management of patients with acute ischemic stroke: a guideline for healthcare professionals from the American Heart Association/ American Stroke Association. Stroke 2013;44:870-947.

19. Saqqur M, Molina CA, Salam A, et al. Clinical deterioration after intravenous recombinant tissue plasminogen activator treatment: a multicenter transcranial Doppler study. Stroke 2007;38:69-74.

20. Zhou L, Ni J, Xu W, et al. High-resolution MRI findings in patients with capsular warning syndrome. BMC Neurol 2014;14:16.

21. Xu X, Wei Y, Zhang X, et al. Value of higher-resolution MRI in assessing middle cerebral atherosclerosis and predicting capsular warning syndrome. J Magn Reson Imaging 2016;44:1277-83.

22. Kawano H, Nakajima M, Inatomi Y, et al. Loading dose of clopidogrel in combination with other antithrombotic therapy for capsular warning syndrome. J Stroke Cerebrovasc Dis 2014;23:1265-6.

23. Fahey CD, Alberts MJ, Bernstein RA. Oral clopidogrel load in aspirinresistant capsular warning syndrome. Neurocrit Care 2005;2:183-4.

24. Chausson N, Joux J, Saint-Vil M, et al. Infarction in the anterior choroidal artery territory: clinical progression and prognosis factors. J Stroke Cerebrovasc Dis 2014;23:2012-7. 
Correction: Intravenous tirofiban therapy for patients with capsular warning syndrome

Li W, Wu Y, Li X, et al. Intravenous tirofiban therapy for patients with capsular warning syndrome. Stroke Vasc Neurol 2019. doi: 10.1136/svn-2018-000163. [Epub ahead of print 9 Jan 2019].

In the Results section of the Abstract, "After treatment, in T-group, four patients (26.7\%) had recurrent attacks, and NIHSS scores were in 11 patients $(73.3 \%)$ at 24 hours" should read "After treatment, in T-group, four patients (26.7\%) had recurrent attacks, and NIHSS scores were 0 in 11 patients (73.3\%) at 24 hours."

Open access This is an open access article distributed in accordance with the Creative Commons Attribution Non Commercial (CC BY-NC 4.0) license, which permits others to distribute, remix, adapt, build upon this work non-commercially, and license their derivative works on different terms, provided the original work is properly cited, appropriate credit is given, any changes made indicated, and the use is non-commercial. See: http://creativecommons.org/ licenses/by-nc/4.0/.

(C) Author(s) (or their employer(s)) 2019. Re-use permitted under CC BY-NC. No commercial re-use. See rights and permissions. Published by BMJ.

Stroke and Vascular Neurology 2019;4:e000163corr1. doi:10.1136/svn-2018-000163corr1

Check for updates 